\title{
VOLCANIC PERIODICITY PLOTS ALONG TRANSITION SERIES, HYPO-HYPER-d-d-INTERELECTRONIC CORRELATIONS AND ELECTROCATALYSIS FOR HYDROGEN ELECTRODE REACTIONS ${ }^{{ }^{*}}$
}

\author{
Jelena M. Jakšić ${ }^{1}$, Velimir R. Radmilović ${ }^{2}$, Nedeljko V. Krstajić́ \\ Časlav M. Lacnjevać ${ }^{4}$, Milan M. Jakšić ${ }^{1,4 *}$ \\ ${ }^{1}$ ICEHT/FORTH, 26500 Patras, Greece \\ ${ }^{2}$ National Center for Electron Microscopy, LBL, University of California, \\ Berkeley, CA 94720,USA \\ ${ }^{3}$ University of Belgrade, Faculty of Technology and Metallurgy, 11000 Belgrade, Serbia \\ ${ }^{4}$ University of Belgrade, Faculty of Agriculture, 11080 Belgrade, Serbia \\ milan@iceht.forth.gr
}

\begin{abstract}
Volcano plots of various physical and chemical properties along transition series reveal the periodicity features of elements based on the d-d-electronic correlations, with rather similar equivalent shape, and consequently, when plotted into one another, yield various relevant linear interdependences. As the consequence, the d-band has been inferred and confirmed for the bonding, adsorptive and catalytic orbital. Such state of evidence leads to the conclusion that on the same way every hypo-hyper-d-d-interelectronic phase diagram behaves similar (local) volcano dependence as the part of the Periodic Table between two initial periods of interacting ingredients. In other words, their intermetallic phases of the same average d-electronic configuration replace the ('missing') elements in their energy state and behaviour in between, and consequently, have been used to assess the synergistically active electrocatalysts for the hydrogen electrode reactions from the peak values of the corresponding volcano plots. In the same context, the general hypsometric type of kinetic relations, including the Boltzmann-Maxwell distribution law that implies the exponential energy dependence, brings various energy states in mutual linear interdependence with the logarithm of the reaction rates.
\end{abstract}

Key words: electrocatalysis; hydrogen evolution (HER); H-adatoms; hypo-hyper-d-d-electronic correlations; intermetallic phase; volcano curve; electrocatalytic synergism; d-d-interactive catalyst grafting; SMSI (Strong Metal-Support Interaction)

\section{ПЕРИОДИЧНОСТ ОД „ВУЛКАНСКИ“ ТИП КАЈ СЕРИЈА ПРЕОДНИ ЕЛЕМЕНТИ, ХИПО-ХИПЕР-d-d-ИНТЕРЕЛЕКТРОНСКИ ВРСКИ И ЕЛЕКТРОКАТАЛИЗА КАЈ ЕЛЕКТРОДНИТЕ РЕАКЦИИ НА ВОДОРОДОТ}

Во низа на преодни елементи од периодниот систем со пораст на редниот број на атомот физичките и хемиските својства се менуваат така што прво растат, достигаат максимум и потоа опаѓаат. Оваа, т.н. вулканска зависност (кривите прилегаат на силуета на вулканско брдо) периодично се повторува и е поврзана со корелацијата меѓу d-d-електроните на овие елементи. При споредба на вредностите од различни периоди се утврдува постоење на линеарна зависност на својствата. Како последица, утврдено е дека d-врската е одговорна за поврзувањето, атсорпцијата и каталитичката активност. Врз основа на овие докази може да се заклучи дека секој хипо-хипер-d-d-интерелектронски фазен дијаграм се однесува на сличен начин. Постојат локални „вулкански“ зависности на одредени својства како во периодниот 
систем надолж преодните серии. Поинаку кажано, нивните интерметални фази со приближно иста d-електронска конфигурација ги заменуваат елементите што недостигаат во таа енергетска состојба, а бидејќи имаат слични својства се користат за постигање синергетски активни електрокатализатори за водородната електродна реакција со максималната вредност како и кај соодветната „вулканска“ зависност.

Во истата насока општиот хипсометриски тип на кинетички релации, вклучувајќи го и BoltzmannMaxwell-овиот закон за дистрибуција, укажува на експоненцијалната зависност на енергијата и ги поврзува различните енергетски состојби во меѓусебна линеарна зависност со логаритамот на брзините на реакцијата.

Клучни зборови: електрокатализа; развивање на водород (HER); Н-адатоми; хипо-хипер-d-dелектроснки врски; интерметална фаза; „вулкански“ тип дијаграми; електрокаталитички синергизам; d-d-интерактивно каталитичко калемење; SMSI (Strong Metal-Support Interaction).

\section{INTRODUCTION}

The aim of the present paper is to reveal and establish the d-d-interelectronic correlations in heterogeneous catalysis and electrocatalysis, and to show an almost axiomatic law that the d-band is cohesive, adsorptive and therefore, the (electro)catalytic orbital. And consequently, to show that volcanic plots along a transition series in the Periodic Table reveal and reflect the natural periodicity properties of elements, and thereby, they appear in a rather similar to the coinciding and overlapping shape of their interplots. As a result of the latter, each hypo-hyper-d-d-interelectronic phase diagram behaves as the part of the Periodic Table between two initial periods of interacting ingredients, with their intermetallic phases of the same average d-electronic configuration replacing the 'missing' elements in their energy state and behaviour in between. Such state of theoretical and experimental facts can then be employed to assess the synergistically active electrocatalysts from the peaks of corresponding volcano plots along each hypo-hyper-d-d-interelectronic phase diagram. Finally, since the hypsometric type of kinetic relations include the BoltzmannMaxwell distribution law with the exponential energy dependence; various energy states can be brought into the mutual linear interdependence with the logarithm of the reaction rates. In such a constellation, the polarization or overpotential at the constant electrode reaction rate, $\left(\eta_{(j=\text { const })}\right)$, for hydrogen and other electrode reactions, as the variable part of the energy of activation and/ or, vice versa, the logarithm of current density $\left((\log j)_{\eta}\right)$ at constant overvoltage (or $\log j_{\mathrm{o}}$ itself, for the exchange current density $\left(j_{\mathrm{o}}\right)$, as the basic kinetic parameter, assessed at $\eta=0$ ), can be interrelated within the d-d-electronic correlations as the linear functions of various energies or physical parametric values, otherwise dependent on the d-electronic configuration and interactions imposed therefrom, and, in general, on the d-electronic band state.

\section{SYMMETRIC VOLCANO PLOTS}

\section{Their General Causes and Consequential Properties}

The broad evidence of akin behaviour of transition elements along the Periodic Table suggests the significance of the Friedel d-delectronic correlations [1-3], to describe the periodicity properties along transition series, since for all reasonable forms of the finite density of states of the d-band $(n(E))$, there results much the same parabolic variation of volcanic plots as when $n(E)=$ const. In other words, $n(E)=10 / w=$ const for $-w / 2 \leq E \leq w / 2$, and $n(E)=0$ elsewhere, where $w$ is the width of the band, the latter being the cause of very strong cohesion observed in transition metals. Thus, the starting point has been a simple tight binding (Huckel) description of the band, which then includes $d$-d-electronic correlations as a 
perturbation. The Brewer [4-6] plots of valencestate bonding enthalpies per unpaired d-electron show the pronounced symmetric inverse volcanic description of cohesive effectiveness, while the far-reaching s,p-band contributes a constant term all along the transition series; the latter confirms the d-band as the cohesive orbital. Such state of experimental evidence restricts the whole model to a simplified picture of the one-d-electron band, where all five semi-d-orbitals with different orbital moments ( $m=2$ to -2 ) are supposed to be equally populated at each energy level, and the total energy band is thereby assumed symmetric with respect to the atomic energy, only d-electron configuration dependent and approximately rectangular. Under such defined circumstances, the number of d-electrons each atom possesses, $n_{d}$, follows from Eq. (1),

$$
n_{d}=\int n(E) d E=\int_{-w / 2}^{E_{F}}(10 / w) d E=10
$$

that yields the Fermi energy $\left(E_{F}\right)$,

$$
E_{F}=(w / 2)\left(n_{d} / 5-1\right)
$$

Cohesive energy results as the energy of state multiplied by the number of states having such energy:

$$
E_{c}=\int_{-w / 2}^{E_{F}} E n(E) d E=\int_{-w / 2}^{E_{F}} E(10 / w) d E=(10 / w)\left(E_{F}^{2}-w^{2} / 8\right)
$$

or, finally, introducing $E_{F}$ from Eq. (2), follows a basic typical parabolic volcano plot,

$$
E_{c}=(5 w / 4) n_{d}\left(n_{d} / 25-2 / 5\right)
$$

with the maximum at $n_{d}=5 \mathrm{~d}$-electrons exactly as the experimental evidence requires. Further corrections for the first order Hartree-Fock correlation, second order Coulombic correlation for intra-atomic and exchange interactions, as

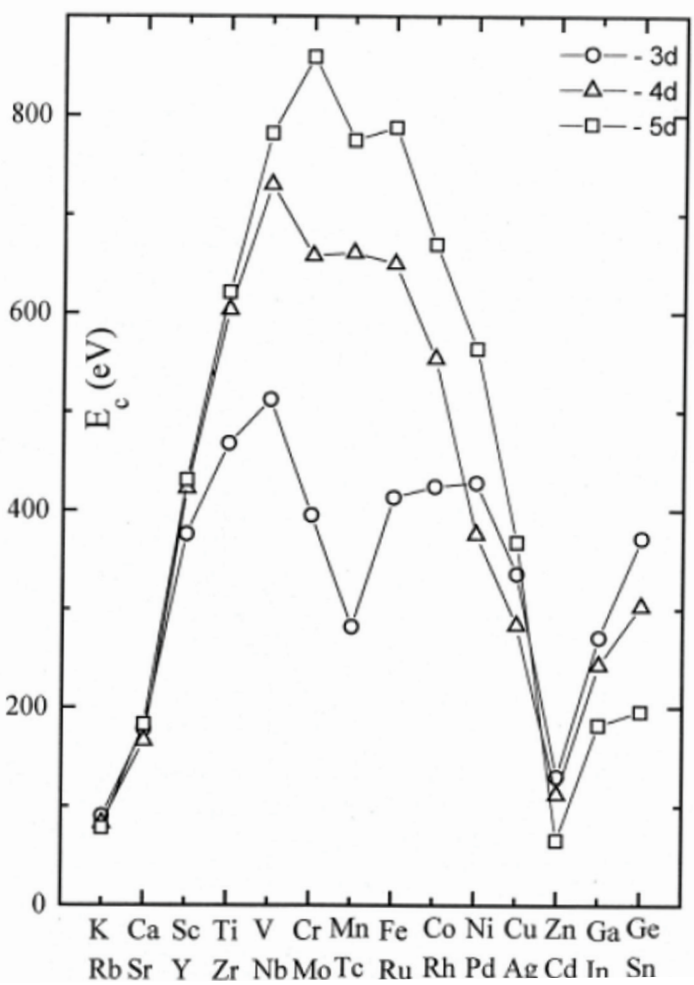

Fig. 1. Cohesive energy $\left(E_{c}\right)$ of transition metals plotted along the Periodic Table $(\mathrm{O}-3 \mathrm{~d}, \Delta-4 \mathrm{~d}, \square-$ $5 \mathrm{~d}$ level (M. M. Jaksic plots of K. A. Gschneidner values [8]).

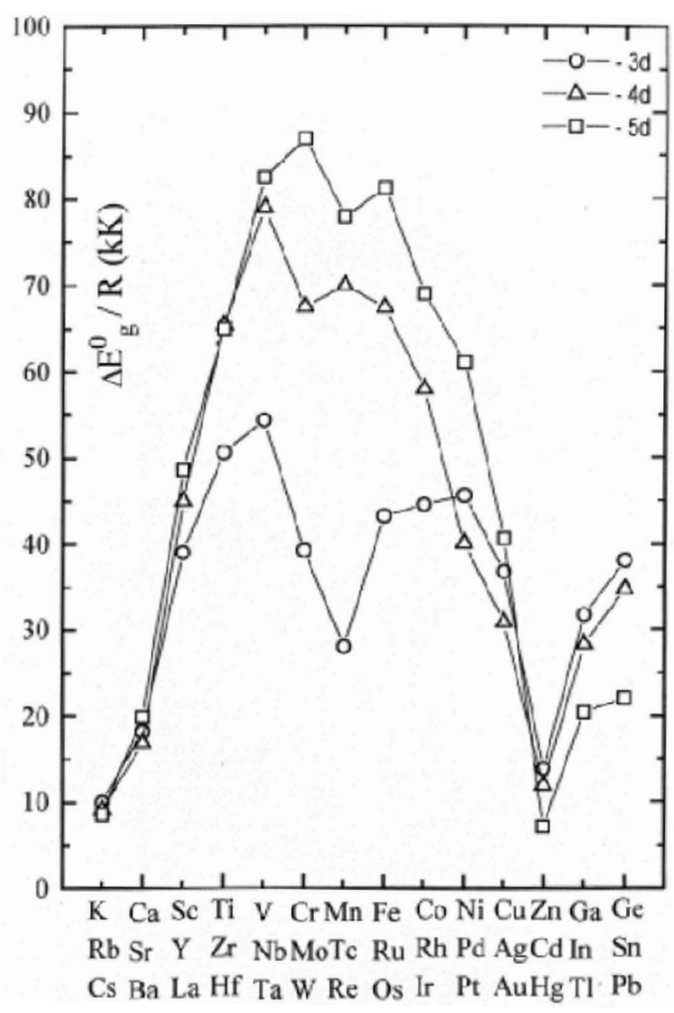

Fig. 2. Individual plot of the energy of vaporization of liquid transition metals $\left(\Delta E g^{\circ} / \mathrm{R}\right)$ along the Periodic Table for ground atomic states at their melting points (M. M. Jaksic plot of L. Brewer values) 
well as corrections for paramagnetic and ferromagnetic features [1-3], have brought the basic parabolic plot to coincide perfectly with the experimental data plotted in Figure 1 and plenty of other congenial akin features (Figure 2).

In such a respect, the majority of physical and chemical features of transition metals, primarily associated with electronic configuration, such as various energy states and interactions based on the latter, obey a typical congenial symmetric type of volcano curves along the Periodic Table, with maximum at the $\mathrm{d}^{5}$-electrons (Figures $1-3$ ) [7], and this way reflect the fundamental periodicity features $[8,9]$. Namely, atomic and molar volume, lattice parameter, melting and boiling point, shear stress, bulk module, cohesive, adsorptive, surface free energy and other similar features are all the reflections of the d-electronic configuration and the resulting interelectronic d-d-bonding effectiveness in any kind of attempt to be overcome or disturbed. Notice,

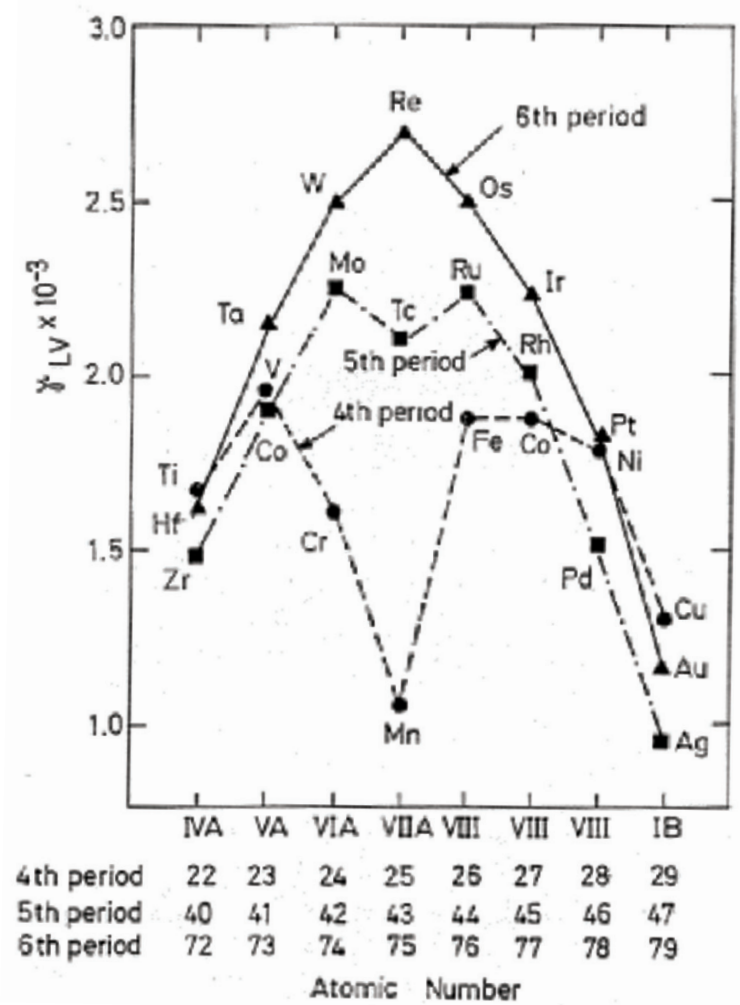

Fig. 3. Surface tension of some liquid metals $\left(\gamma_{\mathrm{LV}}-\right.$ liquid surface tension, dyn $\mathrm{cm}^{-1}$ ) at their melting points versus atomic number along transition series (after B. C. Allen [7]). for example, the specific Mn position in all such volcanic graphs along transition series. Therefore, when one plots cohesive (Figure 1) versus surface free energy (Figure 3 ), or the corresponding volcano curves into one another, there follows a well-defined and experimentally confirmed linear dependence with characteristic $(1 / 6)$ slope $[9,10]$, which shows that the d-band represents both the bonding and adsorptive orbital.

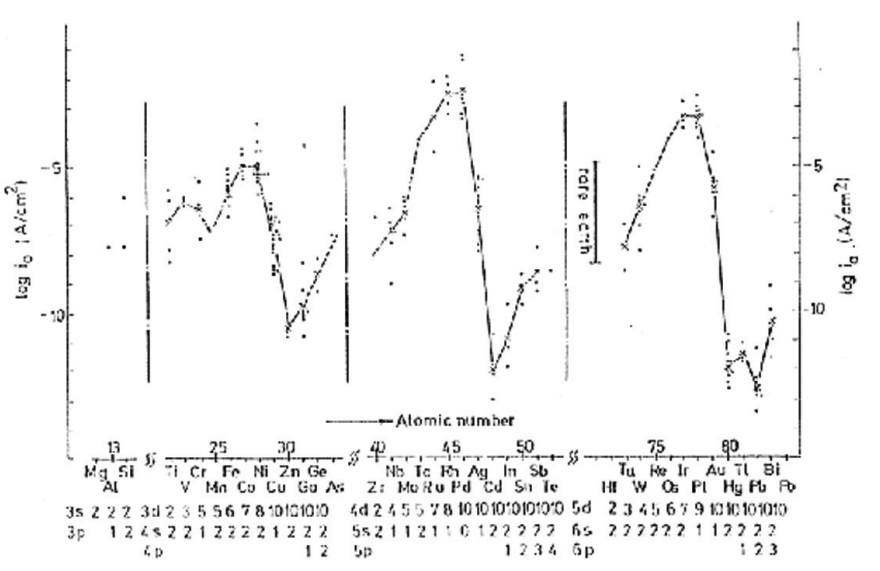

Fig. 4. Values of logarithm of exchange current density $\left(\log j_{\mathrm{o}}, \mathrm{A} \mathrm{cm}^{-2}\right)$ for the HER on various metals plotted along the transition series in acidic media (after Kita [11]).

Electrocatalytic plots for the cathodic hydrogen evolution reaction (HER) along the transition series, meanwhile, follow a typical asymmetric volcano dependence (Figure 4), with maximum at the $\mathrm{d}^{8}$-electrons $(\mathrm{Ni}, \mathrm{Pd}$, Pt) $[11,12]$, in accordance with kinetic laws and requirements. Namely, even the VolmerHeyrowski mechanism,

$$
\mathrm{M}-\mathrm{H}+\mathrm{H}_{3} \mathrm{O}^{+}+\mathrm{e}^{-} \rightarrow \mathrm{H}_{2}+\mathrm{M}+\mathrm{H}_{2} \mathrm{O}
$$

implies two empty d-electron 'seats', or optimal $\mathrm{d}^{8}$-electronic configuration, for the cathodic reaction to occur catalytically facilitated straight on the closest atomic sites of semi-d-orbitals of the same substrate atom, and be enabled to liberate a hydrogen molecule at the maximal electrode activity. This is the reason why the most noble metal, Au, features a sharp drop 
within the volcano plots for electrocatalytic activity along transition series (Figure 4). Otherwise the stoichiometric relation (Eq. (5)) might mislead to the conclusion that the reactive site represents $\mathrm{H}$-adatom $(\mathrm{M}-\mathrm{H})$, which is the reactant, but not the reacting site. In the same sense, the hydrodesulphurisation (HDS) reaction of heterocyclic organic molecules (thiophene, benzothiophene) from oil in petroleum industry, upon transition metal sulphides (dichalcogenides), taken as heterogeneous catalysts in the presence of hydrogen, requires four empty 'seats' per one adsorbing sulphur atom of the reacting species upon d-band and, consequently, the optimal d-electronic configuration arises to be the $\mathrm{d}^{6}[13]$. Thus, the proper kinetic correlation certainly can introduce a simple correction factor and make asymmetric catalytic volcano plots to correlate straightforward with cohesive energy and other symmetric volcanic interdependences on a direct linear manner.

It is interesting and significant that the work function along transition series obeys a rather similar and equivalent asymmetric volcano dependence like the HER [9], with maximum at $\mathrm{d}^{8}$-electrons, too, and consequently, their mutual plot of one into another results in the straight line interdependence $\left(\log j_{\mathrm{o}} \approx k \cdot \Delta \Phi\right)[14]$.

\section{HYPO-HYPER-d-d-INTERELECTRONIC CORRELATIONS AND ELECTROCATALYSIS FOR THE HER}

Characteristic composite volcano curves along the transition series have now been invoked in the search for the synergism in electrocatalytic activity. Namely, while the antibonding d-band of paired d-electrons is consequently unused for cohesive bonding in the lattice of individual transition metals, the former imposes remarkable interactive contribution by its delocalization within the hypo-hyper-d-d-intermetallic combinations. In other words, hypo-hyper-d-d-interelectronic composites of stable intermetallic phases assembled from the ascending or hypo-d-metals and descending or hyper-d-elements, with the same optimal average d-electronic configuration $\left(d^{8}\right)$, already defined for individual transition metals (Figure 4), and in accordance with their cohesive bonding effectiveness, were a priori theoretically predicted for the best and proved synergistic combinations in electrocatalysis for hydrogen and even oxygen electrode reactions [15-20]. Why?

Brewer [4-6] has founded the high temperature thermodynamics and shown that every intermetallic combination between a hypo-d-electronic metal and the semi-series of hyper-d-elements results to a new volcano plot for cohesive bonding along the latter (Figure 5), and vice versa. The bonding effectiveness in such interatomic bonding, alike and as a consequence for the individual transition elements, increases quite markedly from $3 \mathrm{~d}$ to $4 \mathrm{~d}$, and substantially from $4 \mathrm{~d}$ towards $5 \mathrm{~d}$ levels. The same conclusion one derives from individual transition element volcano plots both for cohesive (Figure 1), surface free energy (Figure 3 ) and electrocatalytic activity (Figure 4) along the Periodic Table. In other words, the more exposed d-orbitals, the stronger the cohesive and

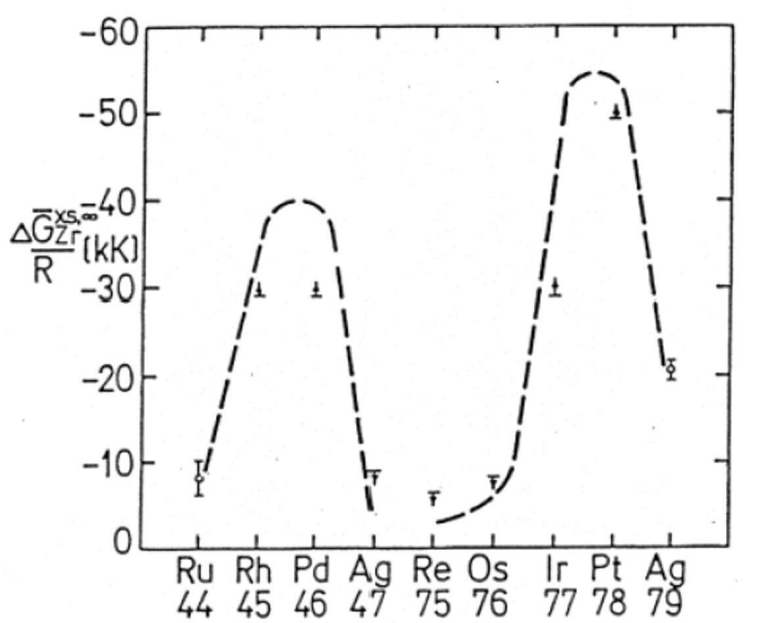

Fig. 5. Excess partial molar Gibbs free energies in $\mathrm{kK}$ of $\mathrm{Zr}$ at infinite dilution within the second and third transition series of platinum group (hyper-d-electronic) elements at 1,800 K (after Brewer [4-6]). Brewer prediction is that the same type volcanic curves of $\mathrm{Hf}$ would be shifted upwards for about $1.2 \mathrm{kK}$, and for Ti downwards for about $1.0 \mathrm{kK}$. 
the weaker the adsorptive bonding, and further consequently, the higher the relative and the optimal electrocatalytic activity values both for the HER (Figure 4) and hydrodesulphurisation reactions [13]). This is one of the most significant fundamental electrocatalytic laws. In such a state of thermodynamic prediction and experimental evidence, for example, for the fifth group d-metals $(\mathrm{V}, \mathrm{Nb}, \mathrm{Ta})$ with only one vacant semi-d-orbital, the interaction between the metals to form corresponding hypo-hyper$\mathrm{d}$-d-intermetallic phases is small with Re, increases substantially with Os, reaches the maximum with Ir, and then decreases with $\mathrm{Pt}$ and $\mathrm{Au}$, while the whole cohesive bonding effectiveness increases and adsorptive strength correspondingly decreases from $\mathrm{V}$ towards $\mathrm{Ta}$. Consequently, for the fourth group d-metals (Ti, Zr, Hf) with two vacant semi-d-orbitals, the maximum in intermetallic interaction and stability is found shifted to the right along the hyper-d-electronic semi-series and lies between the ninth ( $\mathrm{Ir}, \mathrm{Rh}, \mathrm{Co}$ ) and the tenth (Pt, Pd, Ni) group, whereas for the third group (Y, La), the maximum in the volcanic plot for the bonding effectiveness along such a semiseries is located at $\mathrm{Pt}, \mathrm{Pd}, \mathrm{Ni}$, decreasing in the same order $[4-6,15]$. In such an overall general survey, experimental evidence reveals that every hypo-d-element in combination with hyper-d-semi series features an additional volcano dependence with maximum always being located between the $\mathrm{Co}, \mathrm{Rh}$, Ir and $\mathrm{Ni}, \mathrm{Pd}, \mathrm{Pt}$ [4-6]; in other words, just at the average d-electronic configuration, where individual transition metals feature maximal electrocatalytic activity for the HER (Figure 4).

In addition, Brewer [4-6] extended the Hume-Rothery [21] relationship between electronic configuration and crystal structure for individual transition elements to suit for their intermetallic phases: the body-centred cubic $(b c c)$ structure of alkali metals is correlated with an electron configuration $\left(\mathrm{d}^{n-1}\right)$, and when the valence state corresponds to $\mathrm{d}^{n-2} \mathrm{sp}$ or $\mathrm{d}^{n-3} \mathrm{sp}^{2}$, where $n$ is the total number of valence $(n=\mathrm{d}+\mathrm{s}+\mathrm{p})$ electrons, the hexagonal closed packed $(h c p)$ of
$\mathrm{Mg}$ and face centred cubic $(f c c)$ structures of $\mathrm{Al}$ were identified, respectively. In such a respect, the Brewer multiphase and multicomponent hypo-hyper-d-d-interelectronic phase diagrams [4-6], as reliable tools, afford us the ability to estimate and test the optimal average electronic configuration of composite transition metal electrocatalysts. The substance is in the fact that our guides in chemical, physical and crystal morphology are the experimental laws of valence. Since the optimal individual metal electronic configuration for the HER is estimated from the corresponding volcano plots (Figure 4) [11, 12], there remains to establish the d-d-interelectronic correlations for the synergism in electrocatalytic activity of hypohyper-d-d-interelectronic and intermetallic phases, stable and metastable, and along with that, to reveal some accompanying energetic d-d-electronic relations. Namely, since the cohesive bonding effectiveness, surface free energy and electrocatalytic activity all increase from $3 \mathrm{~d}$ towards 5d-level with expanded $\mathrm{d}$-orbitals in the space, some akin interrelations between kinetic or catalytic features and energetic properties might be a priori implied and expected.

\section{VOLCANO PLOTS ALONG HYPO- HYPER-d-d-INTERELECTRONIC PHASE DIAGRAMS AND ELECTROCATALYSIS FOR THE HER}

Since every combination of a hypo-dmetal with any semi-series of hyper-d-elements, and vice versa, almost without exception, results in a new cohesive and other type of volcano plots, and usually appear with rather stable to extra-stable intermetallic phases [4-6], then, as a consequence, all paired bimetallic hypohyper-d-interelectronic combinations, in general, behave in the same sense as the part of the Periodic Table between their individual participating periods of initial ingredients, while the other missing elements in between are replaced by the intermetallic phases of the same average 
d-electronic structure and congenial behavior. Furthermore, their electrocatalytic activity, enthalpy of formation, cohesive, adsorptive, and surface energies follow the same shape of almost coinciding volcano plots (Figure 6). Namely, the same crystal structure implies the same (average) electronic configuration, and consequently, the same physical and chemical properties

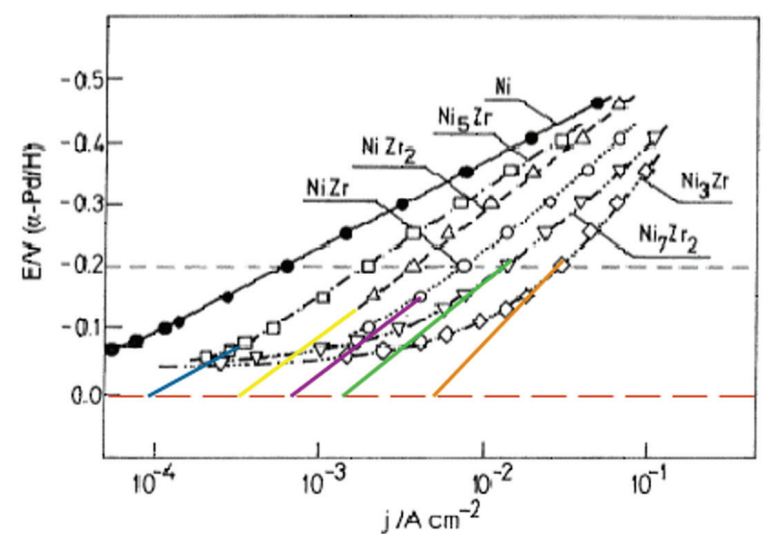

(3) (2)

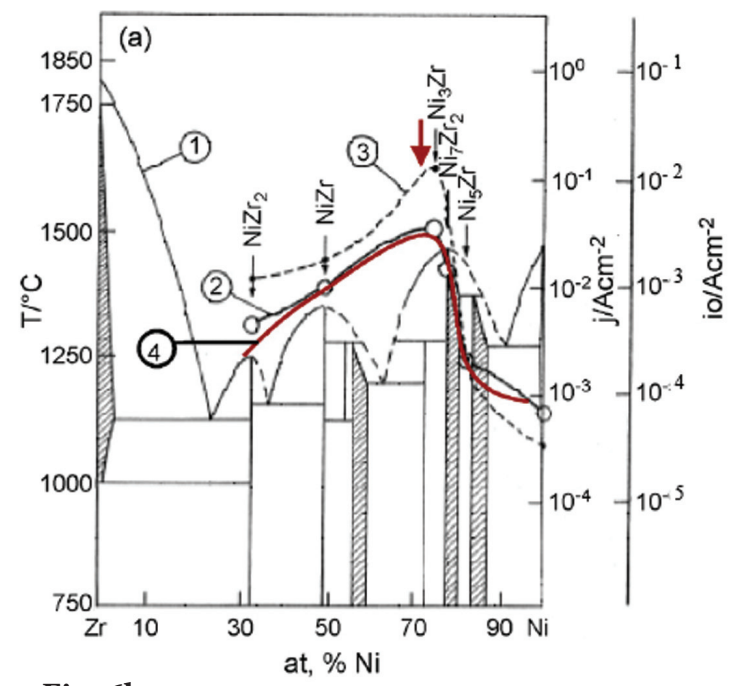

Fig. 6b
[4-6]. Such a state of theoretical prediction and experimental evidence reveal Brewer multiphase and multicomponent diagrams [4-6] with clear isoelectronic phase separating lines. The synergism for the HER, as a consequence, implies such hypo-hyper-d-d-composite intermetallic phases, with prevailing hyper-d-electronic component, which the $f c c$ crystal struc-

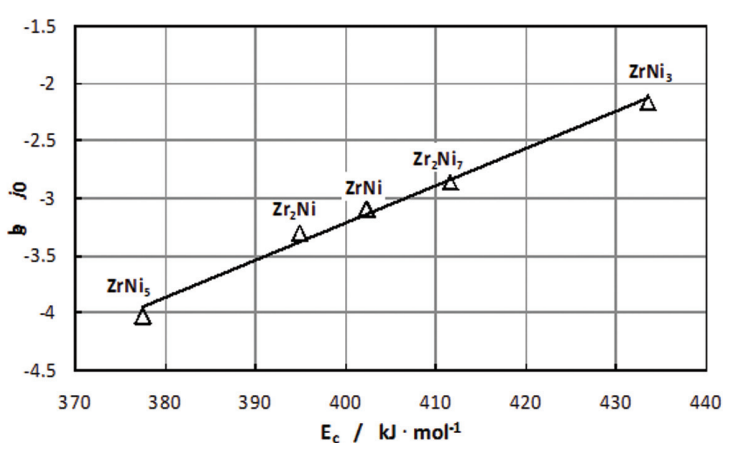

Fig. 6c
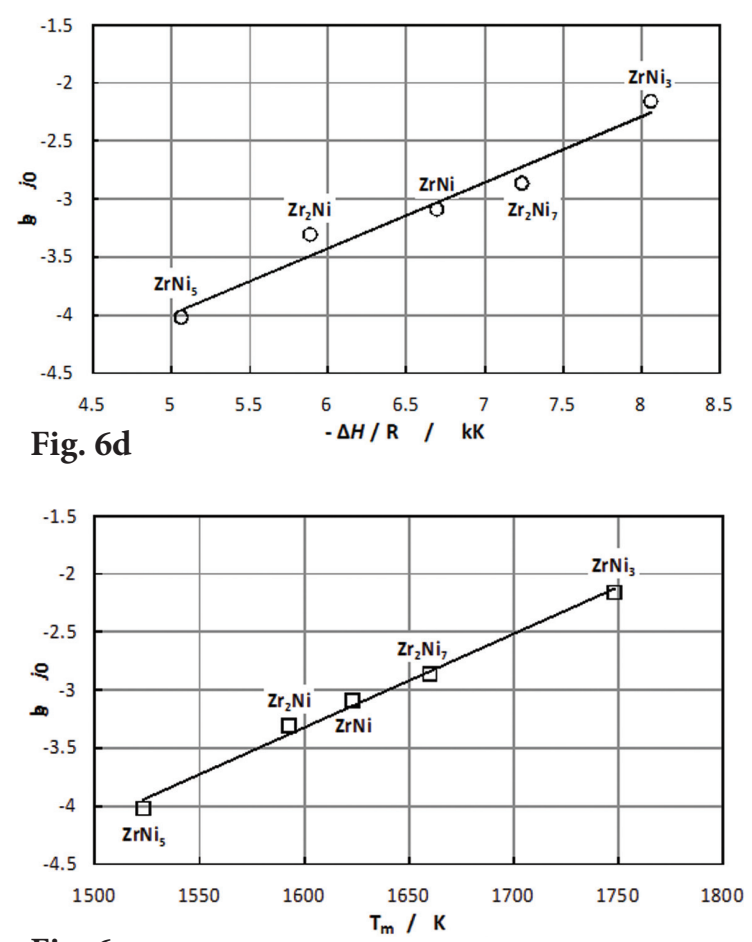

Fig. 6e

Fig. 6 a-e. Electrocatalytic activities of various intermetallic phases (polished below 1.8 in the roughness factor) along $\mathrm{Zr}$ - Ni phase diagram (curve 1 ) for the HER, taken as the exchanged current $(j$, close circles, curve 3 ) and relative current density changes $(j$, closed circuits, curve 2$)$ at constant overvoltage $(-0.2 \mathrm{~V})$, and plotted together with the cohesive energy of intermetallic phases (curve 4). (Fig. 6a: Tafel plots for the HER with indicated extrapolations; Fig. 6b: Electrocatalytic activities along the Zr-Ni phase diagram; Fig. 6c: Linear interdependence between cohesive energy and electrocatalytic activity $\left(\log j_{0}\right)$ for the HER; Fig. 6d: The interplot between free enthalpy of intermetallic bonding and catalytic activity for the HER $(\log j o)$; and Fig. 6e: Linear interdependence between melting points of various $\mathrm{Zr}-\mathrm{Ni}$ intermetallic phases and electrocatalytic activity for the HER $\left(\log i_{\mathrm{o}}\right)$. 
ture approaches the average $\mathrm{d}^{8}$-interelectronic configuration at the peak of cohesive bonding energy along their phase diagram (Figure 6). On the contrary, neither any hypo-hypo-d-d-, nor hyper-hyper-d-d-interelectronic combination leads to any type of volcano dependence, pronounced synergism and/or peak values, but oppositely, consists from linear interchanges of plotted physical parameters along such phase diagrams from the one to the other elemental component.

Since cohesive, adsorptive and surface free energies interrelate with each other in the linear interdependence, as the result, the first principle in electrocatalysis states that the stronger the hypo-hyper-d-d-interelectronic bonding, the less strong the intermediate $(\mathrm{M}-\mathrm{H})$ adsorptive strength at the rate determining step (RDS), and consequently (Sabatier principle in heterogeneous catalysis $[22,23])$, the higher the electrocatalytic activity. Meanwhile, such straightforward mutual interrelations of coinciding volcano plots exist almost without exception for the hypo-hyper-d-d-interelectronic combinations (Figure 6b) [15-20] along their phase diagrams and further afford new linear interdependences. The main conclusion therein has been that the $\mathrm{d}$-orbital is the bonding, adsorptive and electrocatalytic band, and consequently, the synergism in the HER can primarily be sought within the symmetric, strongest bonding and extra-stable hypo-hyper-d-d-interelectronic combinations of interatomic or interionic composites of transition elements [15-20]. In such a context, for example, the extrastable and extremely strong (even explosive) bonding, symmetric intermetallic phase $\mathrm{HfPd}_{3}$, is much more electrocatalytically active for the HER than prevailing noble Pd component itself and behaves insoluble even in aqua regia.

Such a mutual behavior of fundamental theoretical and practical significance has therefore been used as a substantial basis for the search and development of composite synergistically active nanostructured electrocatalysts primarily for the hydrogen (HER) [15, 16], and recently oxygen reduction (ORR) [19, 20, 24] reactions. Namely, the multilinear interrelations amongst akin volcano plots reinforce our theoretical expectances that the common congenial peaks reveal the synergistic points in electrocatalysis. In other words, the straightforward multi-linear interrelations between the cohesive energy (Figure 6c), or, indirectly, the melting points of intermetallic phases along the phase diagram, (Figure 6d), and the bonding enthalpy (Figure 6e), when plotted against each other, or versus the kinetic rate functions $\left(\log j_{\mathrm{o}}\right.$ and/or $\log j)$, at constant overpotential values $\left(\eta_{(j=0)}\right.$ ,$\left.\eta_{(j=\text { const })}\right)$, respectively, reflecting the adsorptive strength (as the result of the variations in cohesive interbonding values), and displaying the electrocatalytic activity (Figure 6), a priori predict by the coinciding peak positions at the corresponding volcano curves the strongest of d-d-interelectronic bonding intermetallic phase, for the optimal composite synergistically active electrocatalysts. Such a conclusion has so far been confirmed by plenty of hypo-hyper-d-d-intermetallic combinations $\left(\mathrm{MoPt}_{3}, \mathrm{MoNi}_{3}, \mathrm{TiNi}_{3}, \mathrm{MoCo}_{3}, \mathrm{HfPd}_{3}\right.$, etc. $)$ $[9,15-20]$. This corresponds to the initial fact, that the stronger the interatomic bonding, the higher the d-electronic density of states, the more strained the interactive d-orbitals, the less strong the adsorptive strength of intermediates in the RDS $(\mathrm{M}-\mathrm{H})$, thereby the easier the cleavage of such decreased adsorptive bonds, and consequently, the highest the resulting synergistic catalytic and electrocatalytic effect at the volcano peak points. Since the optimal d-electronic configuration for maximal electrocatalytic activity in the HER is well known $\left(\mathrm{d}^{8}\right)$ (Figure 4), and since there exists a well defined Brewer [4-6] correlation between the crystal structure and the average d-electronic configuration, such synergistic hypo-hyper-d-d-interelectronic compositions of intermetallic phases follow straight from their phase diagrams. The coincidence between the optimal peaks both of the hypo-hyper-d-d-interelectronic bonding effectiveness (Brewer intermetallic d-d-bonding correlations) [4-6] and the electrocatalytic activity for the HER, confirms such interdepen- 
dences for one of the optimal Brewer $\mathrm{Zr}-\mathrm{Ni}$ hypo-hyper-d-d-interelectronic system [15-20]. For example, the TiNi or YNi combinations, would lead to the individual synergistic $\left(\mathrm{TiNi}_{3}\right.$, $\mathrm{YNi}_{3}$ ) intermetallic phases at the peak values of their cohesive bonding effectiveness, but it could not provide the required optimal average interelectronic configuration and, consequently, could not approach the synergistic activity of $\mathrm{ZrNi}_{3}, \mathrm{MoPt}_{3}$, or $\mathrm{HfPd}_{3}$ electrocatalysts for the HER.

In such a context, the application of such optimal hypo-hyper-d-d-interelectronic composite electrocatalysts of rather stable transition metal intermetallic phases $\left(\mathrm{MoPt}_{3}, \mathrm{ZrNi}_{3}, \mathrm{HfPd}_{3}, \mathrm{WPt}_{3}\right.$, $\mathrm{LaNi}_{5}, \mathrm{CeNi}_{3}$, etc.), with prevailing hyper-d-metal component, both in the intermetallic bonding effectiveness and therefrom resulting increased catalytic activity, has in particular been further advanced, when interactive d-d-bonding supported upon suitable electronic conductive hypo-d-oxide and/or suboxide supports (Magneli phases [19, 20], $\mathrm{Ti}_{\mathrm{n}} \mathrm{O}_{(2 \mathrm{n}-1)}$, or anatase titania, $\mathrm{TiO}_{2}$, zirconia, $\mathrm{ZrO}_{2}$, hafnia, $\mathrm{HfO}_{2}$, tungstenia, $\mathrm{WO}_{3}$, niobia, $\mathrm{NbO}_{2}, \mathrm{Nb}_{2} \mathrm{O}_{5}$, and their composites) [24]. Two mutual achievements have been obtained at once: (i) The SMSI, as an additional d-d-bonding effect, with further consequences on the H-adatoms adsorptive strength and thereby increased electrocatalytic activity, and (ii) The interactive contribution resulting with the continuous spillover or effusion of the primary oxides $(\mathrm{M}-\mathrm{OH})$, as decisive species for the cathodic oxygen reduction (ORR) and CO tolerance [16-20, 24]. In such a respect, the first synergistic electrocatalytic effect for the HER was noticed by the $\mathrm{MoCo}_{3}$ intermetallic d-dinterelectronic combination [25]. In the same context, obviously the $\mathrm{AB}_{3}$ type of intermetallic phases ( $f c c$ crystal structure) feature the synergistic electrocatalytic effect for the HER $\left(\mathrm{ZrNi}_{3}, \mathrm{HfPd}_{3}\right.$, $\mathrm{NbPt}_{3}, \mathrm{MoPt}_{3}, \mathrm{WPt}_{3}$ ), as the consequence of theoretically assessed and experimentally proved optimal average d-electronic configuration.

The recent approach in the density functional theory [26-29], uses the d-band center $\left(\varepsilon_{\mathrm{d}}\right)$, as a parameter which measures the energy of the metal d-states relative to the Fermi energy, to establish the energy of segregation of alloying transition elements and therefrom the adsorption of $\mathrm{H}$-adatoms $[26,27]$ or $\mathrm{CO}[28$, $29]$. The conclusions are quite the same as in the present theory, since segregation is a reciprocal function of cohesive d-d-bonding effectiveness and/or the d-band energy: Chemisorption of $\mathrm{H}$ adatoms decreases with decreasing segregation energy and in the same relation increases the electrocatalytic activity for the HER [27]. Such theory predicts that the prevailing hyper-d-metal, as a host component, pulls inside the phase the hypo-d-constituent of such an alloying composition and the attracting force depends on their hypo-hyper-d-d-intermetallic affinity $[28,29]$. Interactions within two transition metal d-bands are metal dependent and treated as perturbation [27]. Qualitatively there is no difference with the present theory statements, and only the hypo-hyper-d-d-bonding and adsorptive effects become peak-pronounced for the intermetallic phases themselves in the present issues.

In fact functional density calculations (Figures 4 and 5, Ref. [28]) are in good qualitative agreement with the present study. The difference is that the present paper is based on hypo-hyper-d-d-interelectronic correlations all along their phase diagrams in search for rather pronounced peak values and peak positions, while the former uses to calculate interrelating properties within typical mixed alloying properties far from any peaks of symmetric intermetallic phases, with the main intention to avoid any sharp changes and discontinuities. This is the difference between the stable intermetallic phases, which behave as the well defined individual chemical compounds, and mixed alloys featuring as typical mixtures, where ingredients mostly look indifferent in their mutual interaction. 


\section{HYPSOMETRIC ENERGETIC LAWS AND VOLCANIC PERIODICITY FEATURES}

The main point is that all kinetic rate relations obey the hypsometric type of laws with the Boltzmann-Maxwell exponential distribution factor between the already contained thermal (RT) and the necessary activation energy $\left(\Delta H_{a d s}\right.$, enthalpy of intermediate $\mathrm{H}$-adatoms adsorption), the latter being the necessary and enough value enabling intermediates at the RDS to overcome the activation barrier, such as the equation for cathodic exchange current density for the HER,

$$
j_{o}=k_{c} \exp \left(-\frac{z F \Delta H_{d d s}^{o}}{R T}\right)
$$

or the basic relationship in its electrocatalysis. The main conclusive remark is: since the logarithm of the exchange current density $\left(\log j_{\mathrm{o}}\right)$, as the main diagnostic and defining parameter of electrocatalytic activity, stays in the linear interdependence with the standard value of the activation enthalpy for the intermediate $\mathrm{H}$ adatoms $(\mathrm{M}-\mathrm{H})$ adsorption at the $\operatorname{RDS}\left(\Delta H_{\text {ads }}{ }^{\circ}\right)$, the latter must also obey the volcanic periodicity plot both along the transition series and the corresponding hypo-hyper-d-d-interelectronic phase diagrams. The similarity in the shape and the overlap of various volcano plots both along the transition series and hypo-hyper-d-d-interelectronic phase diagrams at the same time enables the plots of one against the others, establishing on such a manner almost endless linear interdependences as in Figure 6. Such state of theoretical and experimental evidence enabled Trasatti $[14,30,31]$ to establish the decisively significant kinetic relation,

$$
\log j_{o} \propto \alpha \frac{\Delta G(M-H)}{R T} \propto \alpha \cdot r \frac{\Delta \Phi}{R T}
$$

where $\Delta \mathrm{G}(\mathrm{M}-\mathrm{H})$ is the gain in free energy associated with adsorption of one mol of $\mathrm{H}$-adatoms, $r$ - the slope $\left(\log j_{\mathrm{o}} v s . \Delta \Phi\right)$, which imposes a fundamental linear dependence in electrode kinetics and electrocatalysis. The latter states that electrocatalytic plots along the energy axis should follow the linear interdependence, where the highest value of $\log j_{\mathrm{o}}$ defines the highest synergistic catalytic activity. Such a mathematical and substantially kinetic relation, when strictly considered and obeyed, would state that any search for the volcano curves within such interdependence (along the energy axis) seems to have no sense, while vice versa, Sabatier principle is equally based on and represents for itself a fundamental law, which implies another type of volcano plots and interdependences. In other words, since $\log j o$ and above stated Trasatti $[14,30,31]$ value of $\Delta \mathrm{G}(\mathrm{M}-\mathrm{H})$ feature typical and similar volcano dependence along three transition series, when plotted one into another, they could by no means obey volcano, but typical straight line dependence. Namely, the d-d-electronic correlations primarily reflect the periodicity and equivalence of the volcano plots along the Periodic Table $[3,4,9]$ and/or along the corresponding hypo-hyper-d-d-interelectronic phase diagrams, while the linear interdependences arise as the consequences in the interplots of the former and the latter, or the akin volcano curves one into another. Plentiful of linearly interdependent values like in Eq. (7), already estimated and plotted Vayenas and co-workers both for solid state electrolytes and aqueous media [32-34] and that way enriched the field. Meanwhile, there are still attempts and issues of volcano plots along some kinetically characteristic energy axis [35], usually since elements with filled-up outermost d-orbitals ( $\mathrm{Au}$, $\mathrm{Ag}, \mathrm{Pb}, \mathrm{Cu}, \mathrm{Hg}$ ), while effectively missing $\mathrm{H}-$ adatoms adsorption, impose some characteristic deviations, and the others [36], still showing the straight $\operatorname{lines}\left(\log j_{\mathrm{o}}\right.$ vs. $E_{a}$, the energy of activation, Figure 3, Ref. [36]), instead of the former.

Since the Fermi energy $\left(E_{F}\right)$ is a straightforward linear function of cohesive $\left(E_{c}\right)$ and thereby surface free energy, too, all the correlations just displayed and discussed in the 
present paper were also already established and implied, based on the Fermi wave vector $\left(k_{F}\right)$ [9, 37-40]. Namely, the Fermi energy represents a multiple of the Rydberg (Ry) constant, Ry = $e^{2} / 2 a_{\mathrm{o}}$, as the ground state bonding energy of the hydrogen atom, $13.6 \mathrm{eV}=2.18 \cdot 10^{-18} \mathrm{~J}$, where $a_{\mathrm{o}}=\left(h / m e^{2}\right)=5.29 \mathrm{~nm}$ is the Bohr radius,

$$
E_{F}=\frac{h^{2} \cdot k_{F}^{2}}{2 m}=\frac{e^{2}}{2 a_{o}} \cdot\left(k_{F} \cdot a_{o}\right)^{2}
$$

while the Fermi wave vector $k_{F}$ defines the radius of a sphere containing the occupied one electron levels, called the Fermi sphere. Thus, the Fermi energy has the magnitude of a typical atomic bonding energy, features the volcano plots along the transition series [36], too, and essentially, suggests the relation with hydrogen adsorption of metals and introduces the simplest correlation of energy terms, just as discussed in the present paper.

Finally, student textbooks in electrochemistry usually conclusively state that Butler-Volmer and simple Tafel relations bring in the linear dependence logarithm of current density and polarization $(\eta=a+b \cdot \log j)$, but cannot a priori answer why overvoltage for the HER is high for $\mathrm{Hg}$ and $\mathrm{Pb}$, and rather low for $\mathrm{Pt}, \mathrm{Pd}$, and $\mathrm{Ni}$. The corresponding volcano plots $[11,12]$ and the d-d-electronic correlations suggest that the filled-up d-orbital with no empty 'seats' for H-adatom adsorption imposes a rather high polarization even for the most noble $\mathrm{Au}$ metal [29], while the optimal $\mathrm{d}^{8}$-electronic configuration provides the highest electrocatalytic properties of transition metals. In other words, the interactive (adsorptive) and non-interactive d-electronic configurations define the degree of polarizability of electrode material for the HER.

\section{CONSEQUENCES AND CONTROVERSIES}

The well-known fundamental principle of Sabatier [22, 23] in heterogeneous catalysis states that for catalysts exhibiting maximum ac- tivity in a given reaction, the surface complexes formed by the reacting molecule upon the catalytic surface or intermediates at the RDS, should have some intermediate heats of formation or adsorption. In other words, the strength of reactant (adatom or surface complex) chemisorption appears decisive in the surface interaction: a rather strong bonding would yield a surface species essentially immobile and exhibiting a high activation energy requirement for further chemical or electrochemical transformation (strong hydride formation). Conversely, a very weak bonding would lead to desorption from the substrate before chemical transformation, the relevant governing quantity here being the enthalpy of adsorption with the correlation of maximum activity with chemisorption bonds which appear to be of intermediate strength. In fact, as concerns the HER, transition metals feature three different interplaying features: (i) The strong to weak hydridic properties along with adsorptive bonding, imposing difficulties to distinguish between themselves and these are most characteristic for almost all hypo-d-elements, (ii) Pure adsorptive sorption of typical catalytic d-metals, and (iii) Non-adsorptive or weakly chemisorptive elements even within noble metals ( $\mathrm{Au}, \mathrm{Ag})$ and elements with the filled outermost d-orbital $(\mathrm{Cu}, \mathrm{Hg}, \mathrm{Pb})$. Such a rather complex situation imposes substantial difficulties of missing reliable experimental data to assess exactly the relationships in catalysis and electrocatalysis. Thus, whatever there has so far been achieved both in heterogeneous catalysis and particularly electrocatalysis, in such a respect, can only be considered more as a reliable indication, than as a definite reliable law, or mostly as a semi-quantitative law. For example, volcano plots of Kita [11] (Figure 4), resulted as a compilation and acquisition of data originating from dozens of laboratories worldwide, when current densities were mostly estimated on the basis of exposed geometric surface, but not on the exact available surface area. In other words, the existing volcano dependence is not questionable at all, but its exact shape. The same concerns to the achievements in the 
present paper (Figure 6), which can be considered as a reliable indication with convincing data only as taken relative one versus others. In other words, we need plenty of such hypohyper-d-d-intermetallic systems even more exactly scanned and assessed to become able for the formulation of laws of general meaning and fundamental conclusions.

Ever since Sabatier formulated his fundamental principle in heterogeneous catalysis, there started search for the Balandin [41, 42] type of volcano plots. A theoretical consideration of fundamental kinetic laws and corresponding equations for the HER has then led Parsons [43-45] and independently Goerischer $[46,47]$ to predict mathematical relations for the existence of a Balandin-type volcano curves $[41,42]$ in electrocatalysis as the plot of the logarithm of the exchange current density $\left(\log j_{\mathrm{o}}\right)$ versus the enthalpy of hydrogen adsorption for various metals. The first and most recognized Balandin type of volcano plot constructed Trasatti [14, 30, 31,48] from recalculated kinetic measurements in the HER and distribution of elements within the obtained graph was exactly as a priori predicted from adsorptive data and electrochemical kinetic behavior of transition metals in hydrogen evolution. Meanwhile, some latter corrections led Trasatti [49] to the straight line dependence. Recently Norskov et al. [35] plotted some reliable values of $\log j_{o}$ for the HER versus DFT (Density Functional Theory) calculated energies of $\mathrm{H}$-adatom chemisorption and achieved some convincingly indicative volcano plot, where the descending branch compose d-metals with filled-up d-band. However, the general base for such calculations has been established on assumption of the equal $\mathrm{H}$-adatom coverages $\left(\Theta_{\mathrm{H}}\right.$ being taken for both 0.25 and 1.0 ), otherwise unattainable for transition elements of filled-up d-orbital. The ascending part of such volcano plots, which consists from hydridic and adsorptive d-elements, has never been disputed and essentially reveals the linear dependence. However, such volcano plots, which primarily depend on the state of d- band, are exactly preserved along the transition series in the Periodic Table of elements. Meanwhile, there are still serious reproaching remarks of reliable authors in the literature $[50,51]$ and the question of volcano plots based on the Sabatier principle in heterogeneous catalysis is still unresolved and needs a more convincing experimental confirmation regardless the reliable theory. Since two theories based one on the straight line dependence and another on the volcano plots along the adsorption energy (enthalpy) axis, substantially exclude each other, sometimes a thesis and antithesis resolve the problem in their synthesis, but electrochemical science still looks for such or another answer.

There is one more interesting aspect of the present paper. Haruta et al. [52]" have shown that the same reactants (propylene admixture with equimolar amounts of hydrogen and oxygen) yield different products upon different nano-sized $\mathrm{Au}$ catalysts supported on anatase titania $\left(\mathrm{Au} / \mathrm{TiO}_{2}\right)$ : (i) Propane by hydrogenation at nano-particles $<2 \mathrm{~nm} \mathrm{Au}$, and (ii) Propylene oxide by epoxidation or oxygen addition for $>2 \mathrm{~nm} \mathrm{Au}$. Hydrogenation implies H-adatom adsorption upon $\mathrm{Au}$ that never spontaneously occurs on a pure massive bulky gold surface. Haruta [53-55] ascribes such chemisorptive properties to "forced" or strained Au-d-orbitals [15-17] within smaller (below the critical threshold) nanostructured metal particles, in particular when d-d-SMSI deposited on the interactive anatase titania. In other words, rather smaller nanostructured $\mathrm{Au}$ particles $(<2 \mathrm{~nm})$, interactively d-d-bonded upon anatase titania $\left(\mathrm{Au} / \mathrm{TiO}_{2}\right)$, thereby being even reinforced in their interbonding effectiveness, and thence exposed with the strained d-orbitals [15-17], are qualitatively something quite else than massive Au. Such highly dispersed nano-particles consequently behave $\mathrm{H}$-adatoms adsorption, and thus feature provided the reversible behavior of hydrogen electrode in the Nernst sense [56], and finally, are able to carry out the hydrogenation processes. Namely, there has also been manifold shown that highly self- 


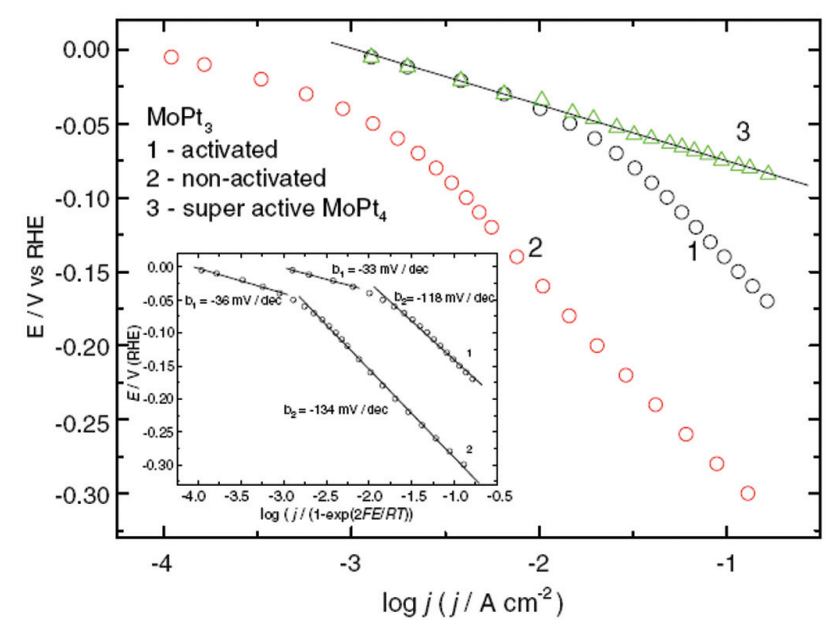

Fig. 7. Polarization curves and corresponding Tafel plots (inset: evaluation of Tafel line slopes) for the HER at $\mathrm{MoPt}_{3}$ and $\mathrm{MoPt}_{4}$ intermetallic phase scanned on the RDE electrodes in $0.5 \mathrm{M} \mathrm{HClO}_{4}$ at $298.25 \mathrm{~K}$ :

(1) activated by polishing and (2) non-activated specimens $\left(\mathrm{MoPt}_{3}\right)$, both being prepolarized at constant cathodic potential ( $-0.150 \mathrm{~V}$ versus $\mathrm{RHE})$, and (3)

fresh activated $\mathrm{MoPt}_{4}$ behaving supper activity under the same measuring conditions.

restructured $\mathrm{Au}$ electrode surface, after multiple potentiodynamic cycles between hydrogen and oxygen evolving limits, equally as highly dispersed nanostructured gold in Haruta sense [52-55], features the pronounced $\mathrm{H}$-adatoms adsorption and even absorption, and further consequently, the reversible electrode properties (M. M. Jaksic et al. [56], and references therein). The restructuration effect has logically been much more pronounced and faster developing in the heavy water media, because of the stronger ineratomic interrelations and deeper penetrating interphase effect of twice larger deuterium than protium ions and atoms [56]. Now, in the light of the present paper considerations, such a highly dispersed Au would take a quite another position along the standard enthalpy axis for H-adatoms sdsorption and similarly so $\mathrm{Ag}$, while $\mathrm{Cu}$ and $\mathrm{Pb}$ with completelly filledup d-orbitals by no means could feature hydrogen chemisorption. Thus, to construct a reliable Balandin type volcano plot in the Sabatier sense, one needs to bring all relevant parameters for a brooad variety of transition metals on the same common denominator (crystal structure, particle size, distinguish between adsorption and absorption amounts, etc.), and on such a way makes them comparable and comeasurable for revealing the volcanic or straight line dependence [57-60].

Finally, there should have to be revealed one more critical view in electrocatalysis. Usually student textbooks tell that Tafel plots for the cathodic hydrogen evolution (HER) and its anodic oxidation (HOR) are symmetric and almost equal along two opposite axis. It might be so for some individual metals, but even not necessarily since metal surface can be and usually is covered with oxides during anodic polarization. However, it is not so for the hypo-hyper-d-dintermetallic phases and alloys. Namely, during cathodic polarization adsorbed $\mathrm{H}$-adatom intermediates keep surface free from oxides [26, 27] and feature maximal synergistic electrocatalytic activities $[15,16]$. Such polarization properties correspondingly reveals Figure 7 for Pt-Mo intermetallic phases [19]. However, since hypod-metals are substantially hydrophilic elements and thereby rather sensitive on water and oxides, thence hypo-hyper-d-d-intermetallic catalysts feature two different electrode properties. While during the cathodic polarization hypo-d-ingredients become pulled inside the intermetallic phase or alloy $[26,27]$ and $\mathrm{H}$-adatoms provide pure metallic interface, during the anodic process the strong water molecule interaction draws them back on the catalyst outer boundary, where they undergo surface oxide coverage and therefore quite another polarization features. The latter can be useful for the $\mathrm{CO}$ tolerance, while for the time being only interactive hypo-d-oxide supported Pt of bronze type satisfies the fast HOR [24].

Acknowledgements. The present paper has been inspired by and based on the Brewer intermetallic bonding theory and the corresponding high temperature thermodynamics, as well as the Friedel d-d-electronic correlations, and highly supported by these two distinguished scientists. This study is friendly dedicated to Professor Sveto Hadži-Jordanov from University 'Kiril and Metodij', Skopje, Makedonija, for his 70th anniversary. 


\section{REFERENCES}

[1] J. Friedel, C. M. Sayers, On the Role of d-dElectron Correlations in the Cohesion and Ferromagnetism of Transition Metals, J. Physique, 38 (1977), 697-705.

[2] J. Friedel, Transition Metals. Electronic Structure of the d-Band. Its Role in the Crystalline and Magnetic Structures, in Physics of Metals, Electrons, J. M. Ziman, Ed., Cambridge Univ. Press, 1 (1969), 340-408.

[3] J. Friedel, Interatomic Correlations of Valence Electrons in Metals, Physica B, 109-110 (1982), 1421-1435.

[4] L. Brewer, Bonding and Structures of Transition Metals, Science, 161 (1968), 115-122.

[5] L. Brewer, Thermodynamic Stability and Bond Character in Relation to Electronic Structure and Crystal Structure,tin Electronic Structure and Alloy Chemistry of Transition Elements, P. A. Beck, Ed., Interscience, New York, 1965, 221-235.

[6] L. Brewer, The Role and Significance of Empirical and Semiempirical Correlations, in Structure and Bonding in Crystals, M. O'Keffe and A. Navrotski, Eds., Academic Press, New York, 1 (1981), $155-174$.

[7] B. C. Allen, The Surface Tension of Liquid Transition Metals at Their Melting Points, Trans. Met. Soc. AIME, 227 (1963), 1175-1183.

[8] K. A. Gschneidner, Physical Properties and Interrelations of Metallic and Semimetallic Elements, in Solid State Physics, Advances in Research and Applications, F. Seitz and D. Turnbull, Eds., Academic Press, New York, 16 (1964), 275-427.

[9] M. M. Jaksic, Volcano Plots along the Periodic Table, Their Causes and Consequences on Electrocatalysis for Hydrogen Electrode Reactions, Journal of New Materials in Electrochemical Systems, $J$. New. Mat. Electrochem. Systems, 3 (2000), 153168.

[10] M. Methfessel, D. Hennig, M. Schefler, Trends of the Surface Relaxations, Surface Energies, and Work Functions of the 4d Transition Metals, Phys. Rev. B, 46 (1992), 4816-4829.

[11] H. Kita, Periodic Variation of Exchange Current Density of Hydrogen Electrode Reaction with Atomic Number and Reaction Mechanism, J. Electrochem. Soc., 113 (1966), 1095-1111; H. Kita, Kinetics and Electrocatalysis. In Encyclo- pedia of Electrochemistry, A. J. Bard, Ed., Marcel Dekker, New York, 9a (1982), 413-556.

[12] M. H. Miles, Evaluation of Electrocatalysts for Water Electrolysis in Alkaline Solutions, J. Electroanal. Chem., 60 (1975), 89-96.

[13] T. A. Pecoraro, R. R. Chianelli, Hydrodesulfurization Catalysis by Transition Metal Sulfides, J. Catalysis, 67 (1981), 430-445.

[14] S. Trasatti, The Work Function in Electrochemistry, in Advances in Electrochemistry and Electrochemical Engineering, C. W. Tobias and H. Goerischer, Eds., Interscience, New York, 10 (1977), 213-321.

[15] M. M. Jaksic, Advances in Electrocatalysis for Hydrogen Evolution in the Light of the BrewerEngel Valence-Bond Theory, J. Mol. Catalysis, 38 (1986), 161-202.

[16] M. M. Jaksic, Hypo-Hyper-d-Electronic Interactive Nature of Synergism in Catalysis and Electrocatalysis for Hydrogen Reactions', Electrochim. Acta, 45, (2000), 4085-4099.

[17] S. G. Neophytides, S. Zafeiratos, G. D. Papakonstantinou, J. M. Jaksic, F. E. Paloukis, M. M. Jaksic, Extended Brewer Hypo-Hyper-d-Interionic Bonding Theory, I. Theoretical Considerations and Examples for Its Experimental Confirmation, Int. J. Hydrogen Energy, 30 (2005) 131-147; II. Strong Metal-Support Interaction Grafting of Composite Electrocatalysts, Int. J. Hydrogen Energy, 30 (2005), 393-410.

[18] S. G. Neophytides, S. H. Zafeiratos, M. M. Jaksic, Selective Interactive Grafting of Composite Bifunctional Electrocatalysts for Simultaneous Anodic Hydrogen and CO Oxidation, I. Theoretical Concepts and Embodiment of Novel Type Composite Catalysts, J. Electrochem. Soc., 150 (2003), E512-E526.

[19] M. M. Jaksic, Lj. Vracar, S. G. Neophytides, S. Zafeiratos, G. Papakonstantinou, N. V. Krstajic, M. M. Jaksic, Structural Effects on Kinetic Properties for Hydrogen Electrode Reactions and CO Tolerance along Mo-Pt Phase Diagram, Surf. Sci., 598 (2005), 156-173.

[20] J. M. Jaksic, N. V. Krstajic, Lj. M. Vracar, S. G. Neophytides, D. Labou, P. Falaras, M. M. Jaksic, Spillover of Primary Oxides as a Dynamic Catalytic Effect of Interactive Hypo-d-Oxide Supports, Electrochimica Acta, 53 (2007), 349-361.

[21] W. Hume-Rothery, The Structure of Metals and Alloys, Institute of Metals, London, 1936; W. Hume- 
Rothery, Electrons, Atoms, Metals and Alloys, Dover, London, 1963.

[22] P. Sabatier, La Catalyse en Chimie Organique, Librairie Polytechnique, Paris, 1913.

[23] P. Sabatier, Hydrogénations et Déshydrogénations par Catalyse, Ber. Deutsch. Chem. Soc., 44 (1911), 1984-2001.

[24] J. M. Jaksic, D. Labou, G. D. Papakonstantinou, A. Siokou, M. M. Jaksic, Novel Spillover Interrelating Reversible Electrocatalysts for Oxygen and Hydrogen Electrode Reactions, J. Phys. Chem. C, 114 (2010), 18298-18312.

[25] C. M. Lacnjevac, M. M. Jaksic, Synergetic Electrocatalytic Effect of d-Metals on the Hydrogen Evolution Reaction in Industrially Important Electrochemical Processes, J. Res. Inst. Catalysis, Hokkaido Univ., 31 (1983), 7-33.

[26] M. Mavrikakis, P. Stoltze, J. K. Norskov, Making Gold Less Noble, Catal. Lett., 64 (2000), 101-106.

[27] G. Greeley, M. Mavrikakis, Alloy Catalysts Designed from First Principles, Nature Mater., 3 (2004), 810-815.

[28] E. Christoffersen, P. Liu, A. Ruban, H. L. Skriver, J. K. Norskov, Anode Materials for Low-Temperature Fuel Cells: A Density Functional Theory Study, J. Catalysis, 199 (2001), 123-131.

[29] B. Hammar, J. K. Norskov, Theoretical Surface Science and Catalysis - Calculations and Concepts, Adv. Catal., 45 (2000), 71-129.

B. Hammer, J. K. Norskov, Why Gold is the Noblest of all the Metals, Nature, 376 (1995), 238 240.

[30] S. Trasatti, Work Function, Electronegativity, and Electrochemical Behaviour of Metals: II. Potentials of Zero Charge and "Electrochemical" Work Functions, J. Electroanal. Chem., 33 (1971), 351378.

[31] S. Trasatti, Development of the Work Function Approach to the Underpotential Deposition of Metals -Application to the Hydrogen Evolution Reaction, Z. Phys. Chem. N.F., 98 (1975), 75-94.

[32] S. G. Vayenas, S. Bebelis, C. Pliangos, S. Brosda, D. Tsiplakides, Electrochemical Activation od Catalysts: promotion, Electrochemical Promotion and Metal-Support Interactions, Kluwer Academic, New York, 2001, and references therein.

[33] Df. Tsiplakides, C. G. Vayenas, Electrode Work Function and Absolute Potential Scale in SolidState Electrochemistry, J. Electrochem. Soc., 148
(2001), E189-E202.

[34] D. Tsiplakides, D. Archonta, C. G. Vayenas, Absolute Potential Measurements in Solid and Aqueous Electrochemistry Using Two Kelvin Probes and Their Implications for the Electrochemical Promotion of Catalysis, Top. Catalysis, 44 (2007), 469-479.

[35] J. K. Norskov, T. Bligaard, A. Logadottir, J. R. Kitchin, J. G. Chen, S. Pandelov, U. Stimming, Trends in the Exchange Current for Hydrogen Evolution, J. Electrochem. Soc., 152 (2005), J23J26.

[36] E. Santos, W. Schmickler, Electrocatalysis of Hydrogen Oxidation - Theoretical Foundations, $A n$ gew. Chem. Int. Ed., 46 (2007), 8262-8265.

[37] M. M. Jaksic, J. M. Jaksic, Fermi Dynamics and Some Structural Bonding Aspects of Electrocatalysis for Hydrogen Evolution, Electrochim. Acta, 39 (1994), 1695-1714.

[38] . M. Jaksic, N. V. Krstajic, B. N. Grgur, M. M. Jaksic, Hydridic and Electrocatalytic Properties of Hypo-Hyper-d-Electronic Combinations of Transition Metal Intermetallic Phases, Int. J. Hydrogen Energy, 23 (1998), 667-681.

[39] N.V. Krstajic, J. M. Jaksic, N. M. Ristic, M. M. Jaksic, Electrocatalysis for Hydrogen Electrode Reactions in the Light of Fermi Dynamics and Structural Bonding Factors. I. Individual Electrocatalytic Properties of Transition Metals, Int. J. Hydrogen Energy, 23 (1998), 1121-1156.

[40] M. M. Jaksic, Hypo-Hyper-d-Electronic Interactive Nature of Synergism in Catalysis and Electrocatalysis for Hydrogen Reactions, Electrochim. Acta, 45 (2000), 4085-4099.

[41] A. A. Balandin, The Theory of Heterogeneous Catalytic Reactions. The Multiplet Hypothesis. Model for Dehydrogenation Catalysis, Z. Physik. Chem., Abt. B, 2 (1929), 289-316.

[42] A. A. Balandin, Modern State of the Multiplet Theory of Heterogeneous Catalysis, Adv. Catalysis, 19 (1969), 1-210.

[43] R. Parsons, The rate of Electrolytic Hydrogen Evolution and the Heat of Adsorption of Hydrogen, Trans. Faraday Soc., 54 (1958), 1053-1063.

[44] R. Parsons, The Kinetics of Electrode Reactions and the Electrode Material, Surf. Sci., 2 (1964), 418-435.

[45] R. Parsons, Electrocatalysis and the Nature of the Electrode, Surf. Sci., 18 (1969), 28-43. 
[46] H. Goerischer, Relation between the Mechanism of Electrolytic Deposition of Hydrogen and the Energy of Adsorption of Atomic Hydrogen on Different Metals, Z. Physik. Chem. N.F., 8 (1956), 137-153.

[47] H. Goerischer, Mechanism of Electrolytic Discharge of Hydrogen and Adsorption Energy of Atomic Hydrogen, Bul. Soc. Chim. Belgrade, 67 (1958), 506-527.

[48] S. Trasatti, Work Function, Electronegativity, and Electrochemical Behaviour of Metals: III. Electrolytic Hydrogen Evolution in Acid Solutions, $J$. Electroanal. Chem., 39 (1972), 163-184.

[49] S. Trasatti, Chemical and Electrochemical Surface Reaction; Role of the Competition Between Solvent and Reaction Intermediate Adsorption, in Proceedings of the Symposium on Electrocatalysis, W. E. O’Grady, P. N. Ross, F. G. Will, Eds., The Electrochemical Society, Inc., Pennington, N.J, 1982, 77-91.

[50] W. Schmickler, S. Trasatti, Comment on "Trends in the Exchange Current for Hydrogen Evolution", J. Electrochem. Soc., 153 (2006), L31-L32.

[51] E. Santos, A. Lundin, K. Poetting, P. Quaino, W. Schmickler, Model for the Electrocatalysis of Hydrogen Evolution, Phys. Rev. B, 79 (2009), 235436-(1-10).

[52] M. Haruta, Size- and Support-Dependency in the Catalysis of Gold, Catal. Today, 36 (1997), 153166.

[53] M. Date, M. Haruta, Moisture Effect on CO Oxidation over $\mathrm{Au} / \mathrm{TiO}_{2}$ Catalyst, J. Catal. 201 (2001), 221-224.
[54] F. Boccuzzi, A. Chiorino, S. Tsubota, M. Haruta, FTIR Study of Carbon Monoxide Oxidation and Scrambling at Room Temperature over Gold Supported on $\mathrm{ZnO}$ and $\mathrm{TiO}_{2}, J$. Phys. Chem., 100 (1996), 3625-3631.

[55] F. Boccuzzi, A. Chiorino, M. Manzoli, P. Lu, T. Akita, S. Ichikawa, M. Haruta, $\mathrm{Au} / \mathrm{TiO}_{2}$ Nanosized Samples: A Catalytic, TEM, and FTIR Study of the Effect of Calcination Temperature on the CO Oxidation, J. Catal. 202 (2001), 256-267.

[56] Krstajic, Lj.M. Vracar, V.R. Radmilovic, S.G. Neophytides, D. Labou, J.M. Jaksic, R. Tunold, P. Falaras, M.M. Jaksic, Advances in Interactive Supported Electrocatalysts for Hydrogen and Oxygen Electrode Reactions, Surf. Sci., 601 (2007), 1949-1966.

[57] E. Wahlstrom, N. Lopez, R. Schaub, P. Thostrup, A. Ronnau, C. Afriich, E. Laegsgaard, J. K. Norskov, F. Basenbacher, Bonding of Gold Nanoclusters to Oxygen Vacancies on Rutile $\mathrm{TiO}_{2}$, Phys. Rev. Lett., 90 (2003), 1-4.

[58] N. Lopez, T. V. W. Janssens, B. S. Claussen, Y. Xu, M. Mavrikakis, T. Bligaard, J. K. Norskov, On the Origin of the Catalytic Activity of Gold Nanoparticles for Low-Temperature CO oxidation, J. Catalysis, 223 (2004), 232-235.

[59] B. K. Min, W. T. Wallace, D. W. Goodman, Support Effects on the Nucleation, Growth, and Morphology of Gold Nano-Clusters, Surf.Sci., 600 (2006), L7-L11.

[60] B. Hammer, Special Sites at Noble and Late Transition Metal Catalysts, Topics in Catalysis, 37 (2006), 3-16. 